\title{
Techno-psychological Aspects of Social Media Behaviors
}

\begin{abstract}
Ali Simsek
Anadolu University, Turkey

Social media has become an inevitable part of our lives in the age of network society. People establish multiple identities for themselves, with or without references to the real world, and behave according to those identities. Self-made components of virtual presence are not limited to identities only; many users also create hyper-personalities for themselves with the help of new technologies. Then, the fundamental question becomes: Why do people create self-made identities and hyper-personalities to portray or hide themselves in social media environments? The answer to this question has certain connections and implications for behaviors of social media users. Therefore, researchers have investigated why some people find social media attractive and attend whenever possible, while others are afraid of social media and hesitate to attend. Positive and negative behaviors of social media users can be classified as braggadocian and preventative. Braggadocian behaviors are related to courageously taking advantage of social media, whereas preventative behaviors are concerned with avoidance of social media. The dominant behavioral pattern of a user depends on what one can achieve through attending or preventing social media. This paper first discusses basic elements of human behavior that drive social media such as altruism, hedonism, connectionism, homophily, multiple identities, memetics, narcissism, and tribalism. Then, it focuses on precautionary elements of human behavior such as avoidance, escape, blocking, fear, hiding, removal, and protectionism. Whether they are attentive or not, one thing is clear: People refrain or enrich their own lives in social media rather than being abused or watching others in industrial media.
\end{abstract}

Keywords: social media, technology behaviors, virtual communication, network society, new media, communication technologies

\section{Introduction}

Social media generally refers to Web-based tools and applications that allow users to share messages and discuss issues through network technologies. Messages, as the contents of communication, may be in any form such as textual, auditory, visual, and multimedia-based. The technologies, which serve as social channels of communication, may include but not limited to Facebook, Twitter, YouTube, Instagram, WhatsApp, Skype, LinkedIn, Flickr, Wikipedia, Google+, and the like.

Social media as a whole is a mobile-based way of communication which focuses on sharing and discussing. Stated differently, social media is the complete set of Internet-based applications that make user-centered creation and dissemination of ideological and technological contents as well as structures possible through Web 2.0 tools (Safko, 2012).

With the emergence of Web 2.0 technology, the use of social media has become possible for all users around the world. It does not only allow users to have access to available contents but also let them add, change, 
erase, share, and comment on messages. Moreover, Web 2.0 allows users a unique opportunity to create and distribute totally new messages. In other words, through new generation of Web technologies, we have changed our communication paradigm from one-way and delayed information sending to multiple-way and synchronous information sharing as individuals of the network society (Castells, 2010).

Considering the rapid proliferation of social media, we can conclude that some people like social media and adopt them quickly. Majority of these people are young and well-educated, although all segments of the population use social media to some extent. The users of social media, including both early adopters and late adopters, cannot think of their personal as well as social life without these tools. That is to say that social media plays an integral part of their lives and they rely on these technologies for many avenues of life.

Taking into account that even the number of users of the most preferred social media tool (i.e., Facebook) is about one-sixth of the world population; some other people are not very excited about and do not use social media. Whatever the reasons are, these people try to continue their lives without social media. They communicate mostly through conventional technologies such as telephones, letters, fax machines etc. Some of these people also use laptops, Internet, mobile phones and the like. They send and receive messages one-on-one but they do not prefer to share messages with many unknown people through social networks.

Then, the fundamental question becomes: "Why some people use social media tools heavily in their daily communication, while others try to ignore and continue their lives without them?" Stated differently, what are the driving forces of action or inaction toward the use of social media? Major motives of using and not using social media can be classified into two categories as braggadocian behaviors and preventative behaviors.

\section{Braggadocian Behaviors}

Social media has a number of benefits for human communication and thus millions of people have discovered those benefits. Considering the burgeoning number of social media users around the world, we can say that there is a serious thirst and demand for social media, regardless of geography and demographics as well as economic and social conditions. Positive attitudes and behaviors of constant social media users can be discussed under certain headings. Although there are many techno-psychological aspects of social media related behaviors, the most common motives or drives can be summarized as follows (Barak \& Suler, 2008); Fennemore cited in Schaefer, 2014; Turkle, 2012).

\section{Altruism}

Altruism can be defined as the unselfish devotion to the welfare of others. Altruistic people always consider the well-being of others so that they try to help them in any way they can. These people may even have significant sacrifices for the good of others. The main purpose of their life is to help and contribute positively to the life of other individuals. Through social media, these people share useful or beneficial information with other users of social networks. They think that the information they share will be helpful to others and make their lives better. They provide free and faster information.

Interestingly, altruistic users in many cases do not know who will actually benefit from the information they share but they still share it. This in part is due to the nature of social media because the originator of the communication process in social media cannot fully determine or control the beneficiaries of the messages. For example, many travelers rate services of hotels where they stayed and share such information with potential future customers of those hotels in order to help them to have a good vacation. Similarly, a Wikipedia author 
contributes to common knowledge base by writing an entry in a subject area but he/she doesn't know who will benefit from the information he/she shares.

\section{Hedonism}

Hedonism is the belief that pleasure is the main goal in people's life. Hedonism has been a part of life since the ancient times but its contents have changed during different centuries. In other words, people have found pleasure in different things depending on the lifestyles of various ages and eras. It appears that since the beginning of the 21st century social media experiences have been a source of pleasure for hundreds of thousands of people all around the world. For example, many users find their old friends in Facebook or enjoy instant multimedia communication through Skype.

Both the activity itself and its contents provide pleasure as well as satisfaction for hedonistic people. Social media users both enjoy utilizing social media as an activity and get pleasure out of accessing to certain activities in networks. They can share their views and comments even by clicking on "Like" button but they are also liked by hundreds of people. They receive positive feedback form those who read or view their contributions. Some profiles even become popular figures with thousands of followers. Some bloggers on social media receive more hits than a columnist in a print newspaper. Even for daily news, as common saying goes, "Bloggers are better than reporters".

\section{Connectionism}

Connectionism refers to the desire to stay in touch with others through social networks. People want to constantly communicate with their relatives, friends, colleagues, buddies, pals etc. anywhere and anytime. Social media provides appropriate opportunities for people to keep up-to-date all the time. They can share what goes on in their lives, whereas they can learn about the lives of other people too. This is also true for public matters. We don't need to wait until evening news on mainstream public media to learn about the events in the world, social media platforms can inform us immediately as the events continue in any part of the world through citizen journalism. It is worth to note that the greeting phrase for one of the social media application is "What's happening?" and the name of another social media application is "WhatsApp".

Social media tools can also help us conduct better and more customized search engines based on the previous data. For example, when a teenage girl who is in the midst of identity crisis and seeks a role model enters the keyword "Paris Hilton", social media tools display the pictures of a famous pseudo-celebrity. However, when a businessman who is a frequent traveller and interested in a reputable accommodation place enters the same keyword, social media search displays information about the Hilton Hotel in Paris. It means that social media tools are relatively smart to understand the needs of the individual users based on previously entered personal data.

Human beings have the dichotomous psychological need to be their own individual, yet they also want to feel that they belong to and are accepted by much larger social set. People are willing to keep open running diaries as a way to stay connected with others because their ultimate desire is to feel good and get accepted. They key with social media is that it allows you to easily stay abreast of people you want to stay connected via causal observation (Qualman, 2009).

\section{Homophily}

Homophily refers to the tendency of human beings to associate with others similar to them. People are usually more comfortable with the company of others who are similar in age, gender, social class, status, 
interests etc. These traits prepare a common ground for beliefs, values, skills, attitudes and so on. As common saying goes "Birds of a feather flock together". Such a common ground generally makes people feel safe and help communication.

Strong sense of homophily may even result in homogamy so that variations in shared social media contents can sometimes help people like differences. However, most people enjoy sharing their views and feelings instead of fighting with those who are insensitive or ignorant about their views and feelings. Peer recommendations play an important role in this regard. For example, hastags on Twitter are strong indicators of homophily showing that people share similar interests as characterized by popular hastags.

\section{Narcissism}

Narcissism is about one's excessive fascination with himself/herself. Narcissistic people like themselves too much, in many instances on the expense of others. They are heavily loaded with themselves so that they take advantage of every opportunity for self-promotion. They feel extremely good about their traits, qualifications, values, and behaviors etc. so that they want other people know and respect their credentials.

A number of reasons may cause for narcissism such as spoiled childhood, deprivation, and self-adoration. However, narcissist people can be easily recognized when they disclose themselves. They tend to be more extraverted and engage in social media activities much more than regular users. For example, some Facebook users share excessive information for self-disclosure to create a positive impression. Of course, they disclose themselves to the extent they want to create fascination toward themselves. The problem is that they share the information in an explicitly selfish manner so that a viewer of his/her web page can easily judge that the owner of the web page has narcissistic personality.

\section{Multiple Identities}

People have at least two identities as given-identity coming on birth and made-identity created in social environments. Given identity includes components such as ethnicity, religion, gender etc. On the other hand, made-identity includes elements such as education, status, occupation etc. The identity of an individual usually consists of all these aspects. Some people are happy and satisfied with their identity, while others experience unhappiness and dissatisfaction throughout their lives. Those who do not feel good about their identity also feel helpless about changing the disturbing elements of their identity in the real life.

However, social media allows people to construct their identity as anything they want. They can change everything when they create their profile in social media. They can even have more than one identity to present themselves as a complete individual. Why do they do this? They probably have some ideals and orientations or certain failures and oppressed desires in their lives so that they can actualize these inner tendencies by having multiple identities (A. Simsek \& E. Simsek, 2014). For example, a fifty year old, brunette, short, and heavy housewife can present herself as a twenty year old, blonde, tall, and slim model in a dating site to find a partner or at least to enjoy responses of men to this new self-made identity or profile. It means that social media lets people exist with any identity they construct so that they can experience a different existence.

\section{Memetics}

The concept of memetics is related to the replication of ideas, feelings, habits, beliefs, and attitudes across individuals. It is commonly known as "meme" and works like copying one's memory to another. A meme often spreads from one person to another within a culture. In order for this to happen, a social media user should first assimilate the original meme, retain in his/her memory for a while, replicate in a way that is observable by 
others, and transmit to other users with the expectation that they will also go through the same viral process to replicate and disseminate the meme.

Proponents describe memetics as an approach to evolutionary models of cultural information transfer. The meme, analogous to gene, is conceived as a unit of culture which is hosted in the minds of one or more individuals, and can reproduce itself by jumping from mind to mind. In this regard, memetics are common ways of information transfer in the cultural area. A meme acts as a unit of carrying certain cultural contents including values, behaviors, ideas, patterns, and practices through appropriate tools and symbols cultural communication. An Internet meme is a concept that spreads rapidly from person to person largely through e-mails, discussion forums, blogs, instant messaging, social networking sites, video hosting services etc. Of course, social media provides worldwide users with incredible opportunities for sharing fashionable or popular intercultural memes. An example of meme may be loading a short video of people singing and dancing "Gangnam Style", a popular Korean song.

\section{Tribalism}

Tribalism can be defined as a person's strong feeling of identity and loyalty toward a specific social group or community. The individual assigns a high value to being associated with that group or community. He does everything to become member of the group; if he/she is already a member, then he/she is proud of it because he/she derives value from being a part of the group or community. Social media users participate in certain networking groups and keep constant communication with members of the desired groups to strengthen their own membership. For example, they feel proud to be a customer of a certain brand and therefore get increasing engagement with other customers of the same brand. In short, tribe members first demonstrate great efforts to enter the tribe and then contribute to the survival, enlargement, and success of their tribes.

What all these drives or motives provide for users of social media is visibility, recognition, and respect. Through their constant communication in social networks, they become more visible figures/characters, let other people know their views and feelings, and as a consequence they are more respected by other individuals. All these mutual behaviors in desired groups provide personal satisfaction and social appreciation for users of social media.

\section{Preventative Behaviors}

Qualman (2009) phrases the essence of preventative behaviors as "What happens in Vegas stays on YouTube". This means that privacy is at risk. Stated differently, social media has certain pitfalls so that some people ignore or constrain their use of social media, mainly due to mass transparency and insufficient knowledge about these technologies. Those who circumvent social media in their lives and do not use these technologies unless it is an obligation can be analyzed under several categories. Unlike braggadocian behaviors, preventative behaviors are similar to each other in nature and closely overlap. Therefore, sometimes it is difficult to distinguish them from one another.

\section{Avoidance}

Some people avoid social media and continue their lives without these tools and applications. They think that they can continue their way of life with traditional technologies and survive without the immersion of popular social media applications. They want a relatively discreet life which is free of the disturbance or occupation of social media messages. Social media as a whole creates stress for them so that they try to avoid 
social media as much as possible. They know that social media is attractive and one cannot stop using them once started to experience so that they try to seek a personal lifestyle without involvement of social media. The basic motive behind this behavior is that people who avoid social media would like to have a simple life and they feel disturbed with the intrusion of social media.

Those avoiding social media think that many profiles or characters in social media environments are not real. Some of them also think social media users do not really care about each other. They often argue that social media users communicate through strange and brief messages which reflect no humane sensitivity or empathy at all. For example, when someone cries for help in the physical life many people help him/her who is in need. However, when people even indicate that they will commit to suicide in social media, nobody cares and the suicide attempt becomes real. Then, "what kind of communication is this?" These kinds of arguments imply that social media cannot replace real life so that there is no need to be a part of this fake world. On the other hand, Turkle (2012) proposes a counter-argument that human beings escape from each other in the real world and expect more from virtual technologies.

\section{Escape}

Those who think that social media are disturbing media try to escape from them as much as they can and do not show personal interest in opportunities or services that social media provides. If they receive a message or invitation through social media, they first review what the message says and then ignore them. The difference between avoidance and escape is that those who avoid social media do not show any interest or involvement in social media, whereas those who escape from social media may show limited interest but do not involve positively. These people think that social media requires sophisticated communication and make their lives complicated if they try to use it.

They also feel that they do not have appropriate skills for effective use of social media. They are considered "digital immigrants" (Prensky, 2001). Therefore, they simply turn their back to avoid problems related to the use of social media. In addition, these people think that there are still many unknown aspects of social media which may potentially create complications difficult to deal with limited skills so that it will be safe to stay away from these technologies (E. Simsek \& A. Simsek, 2013). The tendency to protect personal life is the major drive behind escaping behavior.

\section{Blocking}

Many people associate social media with intrusion. They are afraid that social media violates privacy as well as personal space. They think that when you use a social media tool for a simple and innocent purpose, it never ends there. Social media programs automatically record your data and use such data for many purposes unknown to the originator of the communication process. For example, you schedule an appointment with a doctor but soon you receive a number of messages related to health. Similarly, when you enter a shopping mall, you receive messages regarding sales and discounts in stores located in that mall.

These kinds of intrusions are scary for many people so they are afraid of using social media due to the assumed threat. This fearful attitude results in blocking or rejecting messages coming through platforms of social media, which is eventually reduces the number of social media users or their participation in social media based communication.

People use filtering programs or blockading codes to obstruct unwanted messages; alternatively, they turn off the jamming or impeding functions in their communication devices. Toward this purpose, individual users 
can customize their settings so that they can either block unwanted messages or download such messages on their free time, thereby avoiding addictive immediate response to every incoming message.

\section{Fear}

The sense of fear regarding social media is not only about personal matters or individual life but also about public issues and social life. In some countries, people are afraid of governments when expressing their political views on current or hot issues. They can be identified, arrested, and even tortured just because they shared their views on political matters. Unfortunately, this does not happen only in dictatorships but also in so-called democracies. In recent years, we have observed that a number of governments have tried to block social media platforms during the days of civil disobedience and prosecuted many opposition members exchanging messages through social media such as Twitter, YouTube, and Facebook. Presidents or prime ministers of such countries even threatened social media users on public television (Simsek, 2012).

It is generally observed that the younger the generation, the less concerned they are about privacy. Actually, heavy social media users don't care about every little thing happening in their friend's lives all the time. There are very few exceptional people who view every post, photo or comment. Individual users make personal choices about how they establish their settings and, more important, viewing behavior (Qualman, 2009).

\section{Hiding}

It is basically about not sharing personally sensitive information on social media. People do not put everything about themselves into their social media platforms. There is certain information that they do not want others to learn about them. They take the safe road and hide undesirable or potentially detrimental information. Instead, they present themselves in a selected way, which turns out to be a constructed profile.

This is similar to what goes on in the limited scope of the physical world but the scale is larger in social media because people exist globally due to unlimited range of these tools. Then, the impact may be bigger because many unknown people can learn personal or private things about the profile/character. Therefore, social media users constantly check information available about themselves in social media platforms and try to make sure that they are able to hide information that may be detrimental to their privacy.

\section{Removal}

Many social media users deliberatively select what should be available or accessible about themselves in virtual worlds. They put both personal and public data carefully when presenting themselves in social media platforms. They know that social media represents an electronic public sphere so that they highlight positive information, while avoiding negative or unwanted information about themselves. One may be conscientious about the messages he/she shares but other people can share information about their friends or relatives which may turn out to be harmful for them. Similarly, one's own messages may be misinterpreted by followers and soon become damaging for the original sender of the message.

Every user of social media tries to avoid such situations as much as possible but this is not completely achievable and sometimes undesirable data may be available against their will. In such cases, users prefer to remove those messages quickly. In certain cases they are successful but in some others they are not. For example, a teenage girl may not like to post photos of her former boyfriend but the same boyfriend may put the pictures of his former girlfriend to his social media pages. Then, the girl asks him to remove the relevant photos to prevent possible harm to her. 


\section{Protectionism}

Social media means "bottomless pit" for many people. They cannot completely envision or predict where and to whom their messages go. Social media constitute both personal site and public sphere; people can control and manage these aspects of social media to some extent. However, social media also represents clandestine clouds of information controlled by and accessible to unknown people and/or organizations. In this respect, the users cannot determine who will have access to their personal data and use these data for what purposes. When one thinks about what really goes on behind the curtain, he/she can easily come to the conclusion that being in social media itself is opening up personal data to almost everyone in the world. This is disturbing, if not scary. Thus, many people use social media cautiously when sharing personal information, opinions, and feelings even with close friends and family members.

Social media can also be used for perception management to influence people or divert their attention from facts to deceptions. Much of the information shared through social media may be inappropriate, wrong, dirty, fabricated, biased or incomplete. Therefore, experts usually do not rely on information found in social media, at least they cross-check such information before using it professionally. Maybe knowledgeable people can distinguish factual information from fake information but ordinary people cannot do so and act based on it. Sometimes, this can be dangerous so that people should learn how to protect themselves from fictitious information circulated through social media.

\section{Conclusion}

Social media is a phenomenon of today's life. It appears that this new wave of communication is not a panacea. It will be here for a while. It provides a number of opportunities for all types of communication. The scope of social media includes interpersonal, small group, organizational, community-based, and global communication. This represents virtually unprecedented patterns of communication. Considering the potentials and opportunities of social media, millions of people use social media tools and applications to enhance their communication. However, this new wave of communication is not without pitfalls. It potentially represents many sources of disturbance against personal space and privacy of communication. Therefore, a significant number of people all around the world are cautious about the use of social media, if not scared at all. They even use fake, self-constructed, and multiple identities to protect themselves against potential harms.

Researchers who study on technology-related issues should further investigate both positive and negative aspects of social media usage and their implications on effectiveness, appeal, and efficiency of communication. Similarly, technology experts who develop social media tools and/or applications should be more considerate regarding important psychological aspects of social media usage by various audiences. Finally, communication researchers should investigate the interaction between basic features of new media and common characteristics of the intended users with various backgrounds, which eventually forms individual perceptions about social media.

\section{References}

Barak, A. \& Suler, J. (2008). Reflection on the psychology and social science of cyberspace. In A. Barak (Ed.), Psychological aspects of cyberspace: Theory, research, applications (pp.1-12). Cambridge, UK: Cambridge University Press.

Castells, M. (2010). The rise of the network society. Malden, MA: Wiley-Blackwell.

Prensky, M. (2001). Digital natives, digital immigrants. On the Horizon, 9(5), 1-6.

Qualman, E. (2009). Socialnomics: How social media transforms the way we live and do business. Hoboken, NJ: Wiley. 
Safko, L. (2012). The social media bible: Tactics, tools, and strategies for business success (3rd ed.). Hoboken, NJ: John Wiley and Sons.

Schaefer, M. (2014). The six elements of human behavior that drive social media. Retrieved February 20, 2014 from http://www.businessesgrow.com/2012/02/21/the-six-elements-of-human-behavior-that-drive-social-media/

Simsek, A. (2012). Toward a technology-mediated paradigm of world disorder: Political opposition, social media, and economic invasion. Proceedings of the Second International Communication Symposium on New Media and Social Transformation. Kyrgyzstan-Turkiye Manas University. Bishkek, Kyrgyzstan.

Simsek, A., \& Simsek, E. (2014). Transformation of identities in the mediated landscape of the network society. Online Journal of Communication and Media Technologies, 4(4), 136-153.

Simsek, E., \& Simsek, A. (2013). New literacies for digital citizenship. Contemporary Educational Technology, 4(2), $126-137$.

Turkle, S. (2012). Alone together: Why we expect more from technology and less from each other? New York: Basic Books. 